\title{
Geographic Information Office, Information Technology Office
}

The Geographic Information Office, Information Technology Office (ITO), operating under the Chief Technology Officer, directs the management of U.S. Geological Survey (USGS) information technology (IT) networks and systems supporting the telecommunications, computing, software applications management, and information technology security. The ITO supports IT activities across the nation and works closely with the Department of the Interior's (DOI), Office of the Chief Information Officer.

For more information about ITO activities contact:
Kevin Gallagher
Chief Technology Officer
Crystal Wilson
Administrative Assistant
Faye Lee
Senior Staff Assistant

\section{Collaborative Communications Infrastructure Team}

The Collaborative Communications Infrastructure Team provides the USGS with a communications infrastructure that is a fully connected, virtual organization with anytime, anyplace electronic collaboration using a rich set of tools and services based primarily on Lotus Notes. These tools and services include electronic mail, calendaring, scheduling, office automation, directory services, immediate messaging, real-time collaboration, electronic meeting management, and project collaboration.

Patty Damon Team Lead

\section{Telecommunications Infrastructure Unit}

The Telecommunications Infrastructure Unit provides bureauwide planning, deplcyment, implementation, and operations of telecommunications services (voice, video, and data) to include enterprise operations of GEONET3/Internet 1 and 2 and USGS planning for the DOI-mandated Enterprise Services Network.

Elaine Stout

\section{Unit Chief}

\section{Computing Infrastructure Unit}

The Computing Infrastructure Unit provides bureauwide planning and management related to policies, standards, and guidelines for desktop hardware and software, operating systems, software licensing agreements, hardware contracts, directory services, and domain name services.

Tom Wood

Unit Chief

\section{Call Center Team}

The Call Center Team provides a single point of contact for reporting IT problems. This is an FY04 pilot project in Reston, Va., that will eventually expand to a bureau-wide service.

Terry Sutton

Supervisor

\section{Reston Office Automation Technical Support Team}

The Reston Office Automation Technical Support Team provides desktop and office automation support to all National Center staff. This is an FY04 pilot project in Reston, Va.

Tom Wood

Acting Supervisor

\section{Enterprise Desktop and Software Management Team}

The Enterprise Desktop and Software Management Team provides bureauwide support for enterprise software licensing, usage, and configuration of the Windows operating systems and oversees enterprise hardware contracts and configurations.
Paul Exter
Team Lead

\section{Powell/Enterprise Unit}

The Powell/Enterprise Unit manages the operation of bureauwide and National Center servers, including BASIS+ servers, and provides data management services to the USGS National Center.

Mike Kandrac Acting Unit Chief

\section{Information Technology Security Operations Team}

The Information Technology Security Operations Team (ITSOT) implements IT security policies and assists in the development of IT security standards. The ITSOT operates a bureauwide IT security infrastructure, including a perimeter security (firewall) program, intrusion detection system, vulnerability scanning program, and the CSIRT incident response database.

\section{Lester North Team Lead}

\section{Enclave Certification and Accreditation Team}

The Enclave Certification and Accreditation Team oversees and conducts certification and accreditation (C\&A) for three USGS infrastructure enclaves: Enterprise Web, Office Automation General, and Office Automation Mission Specialized.
Garry Neverdon
Team Lead 